\title{
BMJ Open Knowledge of diabetes and its determinants: a cross-sectional study among adults in a Japanese community
}

\author{
Shino Oba, ${ }^{1,2}$ Mayumi Yamamoto, ${ }^{3,4}$ Yukio Horikawa, ${ }^{5}$ Eiji Suzuki, ${ }^{2}$ \\ Chisato Nagata, ${ }^{6}$ Jun Takeda, ${ }^{5}$ the Gifu Diabetes Study Group
}

To cite: Oba S, Yamamoto M, Horikawa $Y$, et al. Knowledge of diabetes and its determinants: a cross-sectional study among adults in a Japanese community. BMJ Open 2019;9:e024556. doi:10.1136/ bmjopen-2018-024556

- Prepublication history and additional material for this paper are available online. To view these files, please visit the journal online (http://dx.doi. org/10.1136/bmjopen-2018024556).

Received 6 June 2018 Revised 15 January 2019 Accepted 3 April 2019

\section{Check for updates}

(C) Author(s) (or their employer(s)) 2019. Re-use permitted under CC BY-NC. No commercial re-use. See rights and permissions. Published by BMJ.

For numbered affiliations see end of article.

Correspondence to

Dr Shino Oba;

oba@gunma-u.ac.jp

\section{ABSTRACT}

Objective To assess general knowledge of diabetes and its determinants among adult men and women in a Japanese community.

Setting A cross-sectional study with the residential registry in Gifu City. Blood tests were conducted to measure fasting blood glucose levels and the levels after 2 hours of a 75-gram oral glucose load. Participants' previous diagnosis of diabetes and demographic status were identified from a questionnaire. A validated food frequency questionnaire was also administered. To assess the association between good knowledge of diabetes and the level of each factor, a logistic regression was utilised with adjustments for age, education and parental history of diabetes.

Participants A total of 1019 men and women aged 40-78 years.

Primary outcome measure The Diabetes Knowledge Questionnaire was administered. Participants with $\geq 75 \%$ of answers correct were defined as having a good knowledge of diabetes.

Results Previous diagnosis of diabetes was significantly associated with good knowledge of diabetes $(0 R=2.36$; $95 \% \mathrm{Cl} 1.19$ to 4.68). Among individuals with no previous diagnosis of diabetes, age $\geq 60$ years $(0 \mathrm{R}=0.55 ; 95 \% \mathrm{Cl}$ 0.36 to $0.86, p$ value for trend $=0.02$ ) and education $<12$ years $(\mathrm{OR}=0.54 ; 95 \% \mathrm{Cl} 0.30$ to 0.97$)$ were significantly associated with low knowledge of diabetes. The highest tertile intakes of green-yellow vegetables $(0 \mathrm{R}=1.77$; $95 \% \mathrm{Cl} 1.07$ to 2.91 , p value for trend $=0.03$ ) and seafood $(0 \mathrm{R}=1.76 ; 95 \% \mathrm{Cl} 1.04$ to 2.95 , $\mathrm{p}$ value for trend $=0.03$ ) were associated with high knowledge of diabetes.

Conclusions Some diabetes risk factors were implied to determine the general knowledge of diabetes. Conducting further studies of knowledge in various populations is warranted.

\section{INTRODUCTION}

Educating diabetic patients is considered an optimal way of enhancing self-management of the disease, ${ }^{1}$ whereas diabetes education in general populations has been emphasised less. Nonetheless, education of the general public may have potential benefits, such as promoting a primary and secondary prevention by raising awareness of diabetes

\section{Strengths and limitation of this study}

- Knowledge of diabetes and its determinants among 1019 general community-dwelling Japanese men and women selected from the residential registry was assessed.

- In addition to the use of self-administered questionnaire, diabetes status was defined from fasting blood glucose levels and the levels after 2 hours of a 75-gram oral glucose load.

- To the best of our knowledge, this was the first study to thoroughly evaluate the various risk factors of diabetes, including demographic, physical and dietary factors, as potential determinants of diabetes knowledge in a general population.

- The cross-sectional nature of the study limits the potential to show a causal relationship between the suggested determinants and the diabetes knowledge level.

and eliminating prejudice toward diabetic patients. Hence, evaluating the knowledge of diabetes in populations, especially those with a high prevalence of diabetes, can potentially contribute to society.

Several past studies in populations of non-European descent have researched diabetes knowledge and its associated factors. $^{2-7}$ However, the factors examined in these studies were limited to the diabetes status of participants and their relatives or major sociodemographic characteristics. Researching various potential determinants of general knowledge of diabetes in relation to the risk of diabetes is important. Obesity and physical inactivity were the two most important modifiable risk factors of diabetes, ${ }^{8}$ but smoking status and dietary factors also reportedly predict the risk of diabetes. ${ }^{9} 10$ However, no previous studies have thoroughly assessed these risk factors in relation to the knowledge of diabetes in general populations. To identify groups who lack knowledge of diabetes commensurate to their level of risk factors in the general public 
would contribute to a plan for effective education. Hence, the aim of this study was to assess the level of general knowledge of diabetes among middle-aged or older men and women residing in a community in Japan and assess its association with diabetes risk factors.

\section{MATERIALS AND METHODS Study population}

Data was cross-sectionally collected from men and women residing in Gifu City, Japan. The study methods have been described previously. ${ }^{11}$ In brief, men and women aged 40-78 years were randomly selected from the 2005 residential registry. They were invited to visit one of the clinics and hospitals designated for the current study. About 20\% of the invited individuals participated in the study. Data of 1099 participants were confirmed with their diabetes status. Among them, 1019 participants who answered the Diabetes Knowledge Questionnaire (DKQ ${ }^{12}$ were analysed for the current study.

\section{Measurements}

A self-administered questionnaire was conducted at each study site. Knowledge of diabetes was measured with a 24-item version of the DKQ which was originally developed to measure general diabetes knowledge to evaluate diabetes self-management education. ${ }^{12}$ The DKQ was translated into Japanese for the current study by an author of the study (specialising in chronic disease epidemiology) and edited by another author (specialising in diabetes and endocrinology). Age, sex, marital status, employment status, education history, parental history of diabetes and smoking status were asked in the questionnaire. The Intake of food and nutrients was estimated from a validated food frequency questionnaire. ${ }^{13}$ The intake that was reported as risk/protective factors of diabetes ${ }^{10}$ - green-yellow vegetables, seafood, alcohol, coffee, dairy products, magnesium, iron and omega- 6 polyunsaturated fatty acids-was logarithmically transformed and analysed. The dietary glycaemic index and glycaemic load were calculated based on a previously described method. ${ }^{14}$ The nutrient intake and dietary glycaemic load were adjusted for total energy intake by using the residual method proposed by Willett. ${ }^{15}$ The level of physical activity was estimated and transferred into metabolic equivalents-hours/week using a validated questionnaire. ${ }^{16}$ Height and weight were measured at the study site and body mass index (BMI) was calculated from them.

Blood tests were conducted to measure the fasting blood glucose level and the level after 2 hours of a 75-gram oral glucose load. After an overnight fast, the subjects were asked to refrain from taking any medication on the morning of the study. Before conducting an oral glucose tolerance test, a physician interviewed participants and took firsthand measurements of the glucose to evaluate the safety of the oral glucose load. Individuals with diabetes were identified as having fasting plasma glucose $\geq 126 \mathrm{mg} / \mathrm{dL}$, or 2 hours post glucose $\geq 200 \mathrm{mg}$ / $\mathrm{dL}$, in accordance with the criteria of the Japan Diabetes Society. ${ }^{17}$ Prediabetes is a condition of impaired fasting glucose or impaired glucose tolerance or both. Prediabetes was defined as impaired fasting glucose or impaired glucose tolerance, which was referred to as the borderline type ${ }^{17}$ : with a fasting plasma glucose level $\geq 110 \mathrm{mg}$ / $\mathrm{dL}$ and $<126 \mathrm{mg} / \mathrm{dL}$, or a 2-hour plasma glucose level after a $75 \mathrm{~g}$ oral glucose load $\geq 140 \mathrm{mg} / \mathrm{dL}$ and $<200 \mathrm{mg}$ / dL. A previous diagnosis of diabetes was identified with a questionnaire, using the following criteria: individuals who identified their age at their diagnosis of diabetes, who reported periodic visits to a hospital/clinic for the purpose of treatment and controlling their diabetes, who reported taking insulin injections to treat diabetes or who were on medication for diabetes. With the information from blood tests and reported previous diagnosis of diabetes, we classified participants into four groups: those with a previous diagnosis of diabetes, those with undiagnosed diabetes (individuals who had never been diagnosed as having diabetes but whose current blood tests indicated the disease), those with prediabetes (identified from the current blood test) and normoglycaemia participants.

\section{Statistical analysis}

Good knowledge of diabetes was defined as equal to or greater than $75 \%$ of answers correct (18 or more) of 24 items on the DKQ. ${ }^{18}$ Logistic regression analysis was utilised to assess factors associated with good knowledge of diabetes with adjustment for age. The model was additionally adjusted for education and parental history of diabetes as potential confounders, since their association with knowledge of diabetes has been reported previously. ${ }^{3-7}$ The intake of food and nutrients was categorised into tertile groups for analysis. To test for linear trends across categories, the median of each category was included in the logistic models. The Hosmer-Lemeshow test was utilised to test the hypothesis of reasonable fit for all logistic regression models. ${ }^{19}$ The association between knowledge and diabetes status was analysed among all participants. The analysis of the association between diabetes knowledge and diabetes risk factors was limited to those without a previous diabetes diagnosis because it was highly associated with knowledge of diabetes. All the statistical analyses were performed with SAS 9.4 software.

\section{Patient and public involvement}

The study participants were not involved in the design of this study.

\section{RESULTS}

Table 1 summarises the background characteristics of participants, according to a previous diagnosis of diabetes. In 24 questions on the DKQ, the mean number of correct answers was 10.9 (SD 5.3) for participants with no previous diagnosis of diabetes and 13.2 (SD 5.1) for participants 
Table 1 Background characteristics of participants according to diabetes status

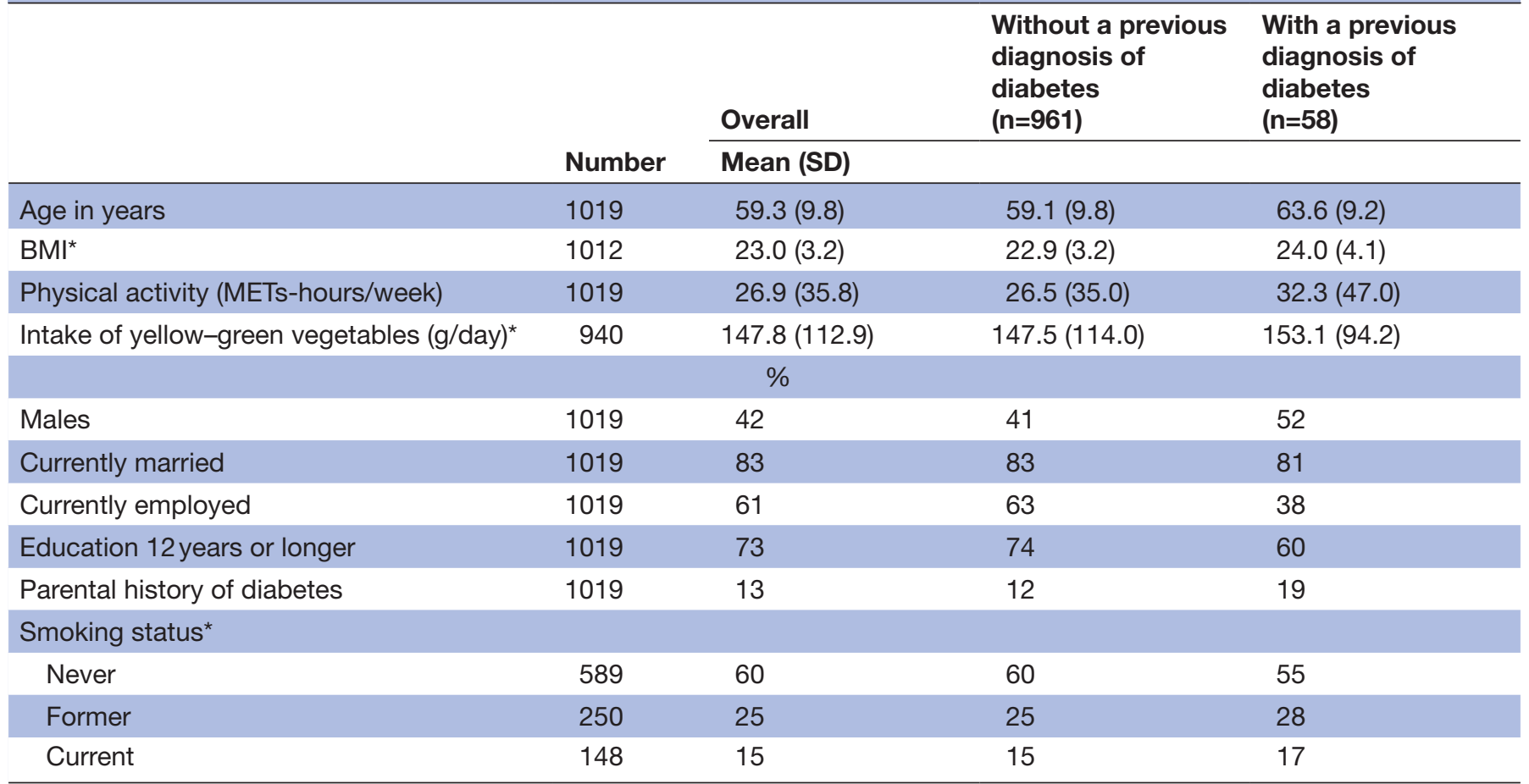

*Individuals with missing value were excluded.

BMI, body mass index; METs, metabolic equivalents.

who had been previously diagnosed with diabetes. Table 2 summarises the relationship between diabetes status and good knowledge of diabetes. As compared with normoglycaemic participants, those with a previous diagnosis of diabetes were significantly more likely to have good knowledge of diabetes. The proportion of correct answers to the DKQ questions was obtained according to a previous diabetes diagnosis (see online supplementary appendix table 1).

Tables 3 and 4 summarise the relationship between good knowledge of diabetes and each factor among individuals with no previous diagnosis of diabetes. Participants who were 60 years old or older were significantly less likely to have good knowledge of diabetes as compared with younger participants. Participants who had less than 12 years of education were significantly less likely to have good knowledge of diabetes as compared with those with more education. Participants with a parental history of diabetes were significantly more likely to have good knowledge of diabetes as compared with those without a parental history; however, the association was attenuated after adjustment for potential confounders. Smokers, especially former smokers, were less likely to have good knowledge of diabetes as compared with never smokers, although statistical significance was not achieved. Participants who had higher intake of green-yellow vegetables and those with higher intake of seafood were significantly more likely to have good knowledge of diabetes. Participants with higher intake of coffee were significantly less likely to have good knowledge of diabetes. Participants whose intake of iron were in the third tertile were significantly more likely to have good knowledge of diabetes as compared with those in the first tertile. The Hosmer-Lemeshow test indicated a good fit for all of the

Table 2 Relationships between diabetes status and good knowledge of diabetes* among Japanese participants

\begin{tabular}{lclll}
\hline & Number & $\begin{array}{l}\text { Good knowledge } \\
\text { of diabetes }\end{array}$ & $\begin{array}{l}\text { Age-adjusted } \\
\text { OR (95\% CI) }\end{array}$ & Adjusted OR† (95\% Cl) \\
\hline Diabetes status & & & 1 & 1 \\
Normoglycaemia & 682 & $13 \%$ & $2.38(1.21$ to 4.68$)$ & $2.36(1.19$ to 4.68$)$ \\
\hline Previous diagnosis of diabetes & 58 & $22 \%$ & $0.96(0.42$ to 2.19$)$ & $0.90(0.39$ to 2.07$)$ \\
Undiagnosed diabetes & 62 & $11 \%$ & $0.81(0.49$ to 1.35$)$ & $0.80(0.48$ to 1.33$)$ \\
\hline Prediabetes & 217 & $10 \%$ & & \\
\hline
\end{tabular}

${ }^{*} \geq 75 \%$ correct answers in the Diabetes Knowledge Questionnaire.

†Adjusted for age (numeric), education 12 years or longer (yes/no) and parental history of diabetes (yes/no). 
Table 3 Relationships between demographic, social and behavioural risk factors of diabetes and good knowledge of diabetes* $^{*}$ among participants without a previous diagnosis of diabetes

\begin{tabular}{|c|c|c|c|c|c|c|}
\hline & $\mathbf{n}$ & $\begin{array}{l}\text { Good } \\
\text { knowledge of } \\
\text { diabetes, \% }\end{array}$ & $\begin{array}{l}\text { Age-adjusted OR } \\
(95 \% \mathrm{Cl})\end{array}$ & $P_{\text {trend }} \dagger$ & $\begin{array}{l}\text { Adjusted } \\
\text { OR‡ }(95 \% \mathrm{Cl}) \\
\end{array}$ & $P_{\text {trend }} \dagger$ \\
\hline \multicolumn{7}{|l|}{ Age§ } \\
\hline$<60$ years old & 470 & 17 & 1 & & 1 & \\
\hline 60 years or older & 491 & 8 & 0.44 (0.29 to 0.66$)$ & $<0.01$ & 0.55 (0.36 to 0.86$)$ & 0.02 \\
\hline \multicolumn{7}{|l|}{ Sex } \\
\hline Male & 395 & 10 & 1 & & 1 & \\
\hline Female & 566 & 14 & 1.33 (0.89 to 2.00$)$ & & 1.33 (0.89 to 2.00$)$ & \\
\hline \multicolumn{7}{|l|}{ Marital status } \\
\hline Married & 797 & 13 & 1 & & 1 & \\
\hline Not married & 164 & 11 & 0.95 (0.55 to 1.63$)$ & & $0.97(0.56$ to 1.68$)$ & \\
\hline \multicolumn{7}{|l|}{ Employmentๆ } \\
\hline Currently employed & 602 & 13 & 1 & & 1 & \\
\hline $\begin{array}{l}\text { Currently not } \\
\text { employed }\end{array}$ & 352 & 12 & 1.47 (0.93 to 2.32$)$ & & 1.49 (0.94 to 2.37$)$ & \\
\hline \multicolumn{7}{|l|}{ Education } \\
\hline 12 years or longer & 707 & 15 & 1 & & 1 & \\
\hline Less than 12 years & 254 & 6 & 0.53 (0.29 to 0.95$)$ & & 0.54 (0.30 to 0.97$)$ & \\
\hline \multicolumn{7}{|l|}{ Parental history of DM } \\
\hline No & 841 & 11 & 1 & & 1 & \\
\hline Yes & 120 & 20 & 1.70 (1.02 to 2.81$)$ & & 1.65 (1.00 to 2.74$)$ & \\
\hline \multicolumn{7}{|l|}{ BMIף } \\
\hline Less than 25 & 737 & 12 & 1 & & 1 & \\
\hline 25 or larger & 223 & 12 & 0.95 (0.60 to 1.51$)$ & 0.60 & 0.94 (0.59 to 1.49 ) & 0.48 \\
\hline \multicolumn{7}{|l|}{ Smoking status } \\
\hline Never & 560 & 14 & 1 & & 1 & \\
\hline Former & 235 & 11 & 0.55 (0.29 to 1.04$)$ & & 0.55 (0.29 to 1.05$)$ & \\
\hline Current & 139 & 9 & 0.83 (0.52 to 1.33$)$ & & 0.85 (0.53 to 1.36$)$ & \\
\hline \multicolumn{7}{|c|}{ Physical activity (METs-hours/week) } \\
\hline First tertile & 420 & 12 & 1 & & 1 & \\
\hline Second tertile & 252 & 13 & 1.02 (0.63 to 1.63$)$ & & 1.01 (0.63 to 1.63$)$ & \\
\hline Third tertile & 289 & 12 & 0.97 (0.61 to 1.54$)$ & 0.91 & 0.92 (0.58 to 1.47$)$ & 0.77 \\
\hline
\end{tabular}

${ }^{*} \geq 75 \%$ correct answers in the Diabetes Knowledge Questionnaire.

$\dagger P$ value for tests of trend from regression analyses with the median value of category as a continuous variable.

$\ddagger$ Adjusted for age (numeric), education 12 years or longer (yes/no) and parental history of diabetes (yes/no).

$\S$ Age in two categories (not in numeric term) was analysed in the model.

IIndividuals with missing value were excluded from the analysis.

BMI, body mass index; DM, diabetes mellitus; METs, metabolic equivalents.

multivariable models $(\mathrm{p}>0.05)$ except for the model with smoking status. It failed to indicate a good fit for several age-adjusted models.

\section{DISCUSSION}

This cross-sectional study among community-dwelling adult men and women in Japan indicated that individuals with a previous diagnosis of diabetes had more knowledge than those without previous diagnosis, which was expected from the previous findings. ${ }^{5}{ }^{20}$ Moreover, we identified certain risk factors of diabetes that were independent determinants of low levels of knowledge about diabetes among individuals without previous diagnosis of diabetes: older age, lower education level and lower intakes of green-yellow vegetables and seafood. Marginally significant low knowledge levels were also 
Table 4 Relationships between nutritional risk factors of diabetes and good knowledge of diabetes* among participants without a previous diagnosis of diabetes

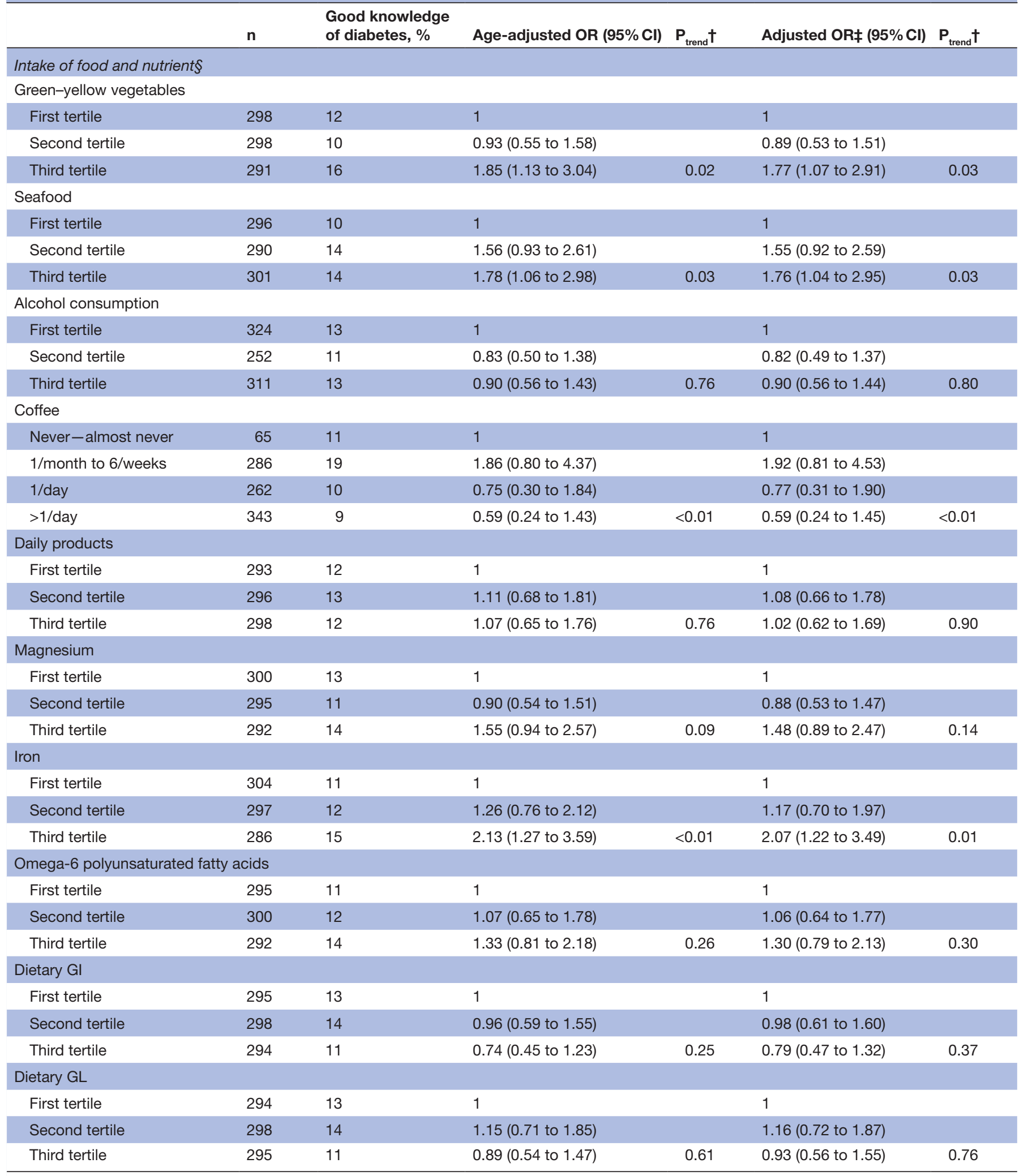

${ }^{*} \geq 75 \%$ correct answers in the Diabetes Knowledge Questionnaire.

†P value for tests of trend from regression analyses with the median value of category as a continuous variable. $\ddagger$ Adjusted for age (numeric), education 12 years or longer (yes/no) and parental history of diabetes (yes/no).

§Individuals with missing value were excluded from the analysis.

Gl, glycaemic index; GL, glycaemic load. 
observed in former smokers. On the contrary, the level of risk and knowledge were positively associated with some other risk factors: the intakes of coffee and iron. To the best of our knowledge, this study was the first to thoroughly evaluate the various risk factors of diabetes, including demographic, physical and dietary factors, as determinants of knowledge of diabetes in a general population. These findings indicate that the effective diabetes education for the general public involves targeting those with observed diabetes risk factors.

The association between general knowledge of diabetes and dietary intake has not been widely evaluated in general populations. A study of diabetes patients supports our finding, as individuals with lower nutrition knowledge had lower intake of fruit and vegetables. ${ }^{22}$ Two studies among general populations in the UK also support our finding, that knowledge of the links between diet and disease is positively correlated with the intake of vegetables or vegetables and fruit combined. ${ }^{23} 24$ However, the knowledge assessed in these studies was for diseases in general, not specifically for diabetes. Another study reported the positive association of fish intake with knowledge of diet and diseases; however, the study was conducted among medical students, and the association was observed only among students with high fibre intake. ${ }^{25} \mathrm{~A}$ further related previous study reported that among general populations, individuals who made conscious efforts to eat a healthy diet were more likely to consume high amounts of vegetables. ${ }^{26}$ These studies assessed the knowledge of nutrition and disease; however, our study specifically assessed knowledge of diabetes and its association with healthy eating behaviours, which included the intakes of green-yellow vegetables and seafood. The association was possibly mediated by health-conscious attitudes. Meanwhile, the association of knowledge with the intake of coffee or iron was not the same, and high-risk individuals were more likely to have good knowledge of diabetes. The observed inconsistency may be caused by the fact that the beneficial or adverse effects of the intakes of coffee and iron are not yet widely known in public. An inverse association between coffee intake and the risk of diabetes was published in $2002^{27}$; until then, there had been some debate about the role of caffeine in the development of diabetes. ${ }^{28}$ Likewise, the role of body iron in the risk of developing diabetes is only supported by emerging evidence. ${ }^{29}$ Because of that, consumption of coffee and food rich in iron may not be linked to health-conscious attitudes. Moreover, residual confounders may have influenced the results.

The current study has several limitations. The participation rate was low, and our participants may not accurately reflect the general population in the community. The prevalence of diabetes is lower than the national estimation, ${ }^{30}$ and we assume that health-conscious individuals were more likely to participate in the current study. In such a case, the observed associations between risk factors and diabetes knowledge are robust, as they were observed among participants whose level of diabetes knowledge was higher and less varied than that of the general population. Risk factors and previous diagnosis of diabetes were self-reported, yet the blood glucose levels and BMI were estimated from measured values. Although we adjusted for age, education and parental history of diabetes in the analysis, the study could not rule out the possibility of residual confounders. Despite these limitations, important information can be obtained from the current results, since few data exist on the knowledge of diabetes and its determinants, and no studies have extensively evaluated diabetes risk factors as determinants of knowledge.

In conclusion, good knowledge of diabetes is lower in individuals without a previous diagnosis of diabetes as compared with those with a previous diagnosis among adult men and women in a Japanese community. We further observed some diabetes risk factors were determinants of low knowledge of diabetes, which were old age, a lower education level, the low intakes of green-yellow vegetables and seafood, and possibly past smoking status. Conducting further research to seek target groups for effective education to raise the knowledge of diabetes in populations is an asset.

\section{Author affiliations}

${ }^{1}$ Graduate School of Health Sciences, Gunma University, Maebashi, Gunma, Japan ${ }^{2}$ Department of Prevention for Lifestyle-related Diseases, Gifu University Graduate School of Medicine, Gifu, Japan

${ }^{3}$ Health Administration Center, Gifu University, Gifu, Japan

${ }^{4}$ United Graduate School of Drug Discovery and Medical Information Sciences, Gifu University, Gifu, Japan

${ }^{5}$ Department of Diabetes and Endocrinology, Gifu University School of Medicine Graduate School of Medicine, Gifu, Japan

${ }^{6}$ Department of Epidemiology and Preventive Medicine, Gifu University Graduate School of Medicine, Gifu, Japan

Acknowledgements We thank all of the on-site physicians in the Gifu area who joined this study for their medical support.

Collaborators The Gifu Diabetes Study Group members are: Drs K Adachi, $K$ Chimori, Y Morimoto, Y Kimata, H Hayashi, M Ishii, M Izai, K Kamikubo, Y Kanoh, T Kojima, T Komaki, J Kosaka, H Maekawa, M Murayama, E Suzuki, K Yoshino, M Matsuda, I Matsui, S Ozeki, S Sakata, H Sarui, N Takeda, M Sugimoto, R Totani, H Wada, Y Wada, M Yokoyama, M Araki, E Goshima, H Daido, K Nagai, K Fushimi, M Kitada, M Hayashi, T Imai, N Kojima, M Sato, H Murase, T Nagashima, N Noritake, Y Noda and K Ohmae.

Contributors MY, ES, CN and JT designed the study. MY, ES and SO coordinated the study and collected data. SO conducted data analysis, and interpretation were conducted by SO, CN, MY and YH. All authors were involved in the drafting of the manuscript, led by SO. All authors reviewed each draft of the manuscript, and approved the final version of the manuscript.

Funding This work was supported in part by grants from the Ministry of Education, Science, Sports and Culture of Japan.

Competing interests None declared.

Patient consent for publication Obtained.

Ethics approval This study got ethical approval from the Ethics Committee of Gifu University Graduate School of Medicine.

Provenance and peer review Not commissioned; externally peer reviewed.

Data sharing statement № additional data are available.

Open access This is an open access article distributed in accordance with the Creative Commons Attribution Non Commercial (CC BY-NC 4.0) license, which permits others to distribute, remix, adapt, build upon this work non-commercially, and license their derivative works on different terms, provided the original work is properly cited, appropriate credit is given, 
any changes made indicated, and the use is non-commercial. See: http:// creativecommons.org/licenses/by-nc/4.0/.

\section{REFERENCES}

1. Chatterjee S, Khunti K, Davies MJ. Type 2 diabetes. Lancet 2017;389:2239-51.

2. Wee HL, Ho HK, Li SC. Public awareness of diabetes mellitus in Singapore. Singapore Med J 2002;43:128-34.

3. Al Shafaee MA, Al-Shukaili S, Rizvi SG, et al. Knowledge and perceptions of diabetes in a semi-urban Omani population. BMC Public Health 2008;8:249.

4. Gunay T, Ulusel B, Velipasaoglu S, et al. Factors affecting adult knowledge of diabetes in Narlidere Health District, Turkey. Acta Diabetol 2006;43:142-7.

5. Murugesan N, Snehalatha C, Shobhana R, et al. Awareness about diabetes and its complications in the general and diabetic population in a city in southern India. Diabetes Res Clin Pract 2007;77:433-7.

6. Ceballos RM, Coronado GD, Thompson B. Having a diagnosis of diabetes is not associated with general diabetes knowledge in rura Hispanics. J Rural Health 2010;26:342-51.

7. Baptiste-Roberts K, Gary TL, Beckles GL, et al. Family history of diabetes, awareness of risk factors, and health behaviors among African Americans. Am J Public Health 2007;97:907-12.

8. Tabák AG, Herder C, Rathmann W, et al. Prediabetes: a high-risk state for diabetes development. Lancet 2012;379:2279-90.

9. Willi C, Bodenmann P, Ghali WA, et al. Active smoking and the risk of type 2 diabetes: a systematic review and meta-analysis. JAMA 2007;298:2654-64.

10. Ley SH, Hamdy O, Mohan V, et al. Prevention and management of type 2 diabetes: dietary components and nutritional strategies. Lancet 2014;383:1999-2007.

11. Oba S, Suzuki E, Yamamoto M, et al. Active and passive exposure to tobacco smoke in relation to insulin sensitivity and pancreatic $\beta$-cell function in Japanese subjects. Diabetes Metab 2015;41:160-7.

12. Garcia AA, Villagomez ET, Brown SA, et al. The Starr County Diabetes Education Study: development of the Spanish-language diabetes knowledge questionnaire. Diabetes Care 2001;24:16-21.

13. Shimizu H, Ohwaki A, Kurisu Y, et al. Validity and reproducibility of a quantitative food frequency questionnaire for a cohort study in Japan. Jpn J Clin Oncol 1999;29:38-44.

14. Oba S, Nagata C, Nakamura K, et al. Dietary glycemic index, glycemic load, and intake of carbohydrate and rice in relation to risk of mortality from stroke and its subtypes in Japanese men and women. Metabolism 2010;59:1574-82.
15. Willett W. Implication of total energy intake for epidemiological analyses. Nutritional epidemiology. Oxford University Press: Oxford, 1990.

16. Suzuki I, Kawakami N, Shimizu H. Reliability and validity of a questionnaire for assessment of energy expenditure and physical activity in epidemiological studies. J Epidemiol 1998;8:152-9.

17. Kuzuya T, Nakagawa S, Satoh J, et al. Report of the Committee on the classification and diagnostic criteria of diabetes mellitus. Diabetes Res Clin Pract 2002;55:65-85.

18. Cántaro K, Jara JA, Taboada M, et al. Association between information sources and level of knowledge about diabetes in patients with type 2 diabetes. Endocrinol Nutr 2016;63:202-11.

19. Hosmer DW, Lemshow S. Applied logistic regression. New York, NY: Wiley \& Sons Inc, 2000

20. Yun LS, Hassan Y, Aziz NA, et al. A comparison of knowledge of diabetes mellitus between patients with diabetes and healthy adults: a survey from north Malaysia. Patient Educ Couns 2007;69:47-54

21. Arora S, Marzec K, Gates C, et al. Diabetes knowledge in predominantly Latino patients and family caregivers in an urban emergency department. Ethn Dis 2011;21:1-6.

22. Breen C, Ryan M, Gibney MJ, et al. Diabetes-related nutrition knowledge and dietary intake among adults with type 2 diabetes. $\mathrm{Br}$ J Nutr 2015;114:439-47.

23. Wardle J, Parmenter K, Waller J. Nutrition knowledge and food intake. Appetite 2000;34:269-75.

24. Baker $\mathrm{AH}$, Wardle J. Sex differences in fruit and vegetable intake in older adults. Appetite 2003;40:269-75.

25. Jovanović GK, Kresić G, Zezelj SP, et al. Cancer and cardiovascular diseases nutrition knowledge and dietary intake of medical students. Coll Antropol 2011;35:765-74.

26. Kearney JM, Gibney MJ, Livingstone BE, et al. Attitudes towards and beliefs about nutrition and health among a random sample of adults in the Republic of Ireland and Northern Ireland. Public Health Nutr 2001;4:1117-26.

27. van Dam RM, Feskens EJ. Coffee consumption and risk of type 2 diabetes mellitus. Lancet 2002;360:1477-8.

28. Ding M, Bhupathiraju SN, Chen M, et al. Caffeinated and decaffeinated coffee consumption and risk of type 2 diabetes: a systematic review and a dose-response meta-analysis. Diabetes Care 2014;37:569-86.

29. Zhao Z, Li S, Liu G, et al. Body iron stores and heme-iron intake in relation to risk of type 2 diabetes: a systematic review and metaanalysis. PLoS One 2012;7:e41641.

30. Ministry of Health, Labour and Welfare. The National Health and Nutrition Survey in Japan, 2006, 2009. 